\title{
The Impact of Constituency Campaigning in the 2001 General Election
}

\section{David Denver (Lancaster University), Gordon Hands (Lancaster University), Justin Fisher (Brunel University) and Iain MacAllister (Lancaster University)}

Among the most interesting developments in British elections during the 1990s was the increased attention given to constituency campaigning by the major parties. Having been eclipsed by television and the national campaign since the 1960s, and consistently downgraded in importance by academic analysts, local campaigning was revitalized. There were a number of reasons for this, including the development of personal computers, the campaigning possibilities opened up by telephone canvassing and an increasingly professional approach to campaigning on the part of staff at party headquarters. The revival of the parties' enthusiasm for constituency campaigning was matched by, and in part also encouraged by, renewed interest on the part of academics whose work significantly revised the prevailing orthodoxy about the impact of local campaigning. Far from being a 'ritual', undertaken by party workers out of habit, a series of studies by three separate groups of researchers provided clear and persuasive evidence that local campaigning affected election outcomes. Measuring the strength of campaigns in various ways, Seyd and Whiteley, Johnston, Pattie and colleagues, and Denver and Hands demonstrated that in recent elections variations across constituencies in the intensity of campaigns mounted by the parties were associated with variations in their electoral performance (see, for example, Denver and Hands, 1997, 1998; Denver, Hands and Henig, 1998; Johnston, Pattie and Fieldhouse, 1995; Whiteley and Seyd, 1994). There are some areas of disagreement between these research teams - on whether Conservative campaigning has been as effective as that of the other major parties, for example, and on whether campaigns by incumbent parties were as effective as those of challengers - but there is substantial agreement on the central point: at least as far as Labour and Liberal Democrats are concerned, constituencies which mount strong campaigns generally achieve better results than those whose campaigns are weaker.

It is worth emphasising, however, that most of the evidence supporting this conclusion has come from the general elections of 1992 and 1997. In both of these elections the electoral context was similar - the Conservatives were in government and on the defensive. In advance of the elections it was widely anticipated that Labour would improve its position and, on past form, the Liberal Democrats would also have been expected to benefit with an unpopular 
Conservative government in office. Denver and Hands' work suggested that in 1992 and 1997 more effective Labour and Liberal Democrat campaigning clearly improved their performance but that this was not the case for the Conservatives. Although their results for 1997 were more ambiguous than those for 1992, it appeared that in both elections Conservative local campaigning did not significantly improve Conservative performance. ${ }^{1}$

In 2001, however, the electoral context was different. Labour was now in government and on the defensive - concerned mainly to hold on to seats rather than make new gains - while the Conservatives hoped, and probably expected, to make some advance from the low point of 1997. The Liberal Democrats were also in a novel situation. Having made an unexpectedly large number of gains in 1997, they had more than the usual handful of seats to defend. This changed context clearly affected the targeting strategies of the parties - the Conservatives and Labour, in particular, targeted many more constituencies than normal. ${ }^{2}$ Whether the changed context would affect the ability of local campaigns to mobilize voters remained to be seen, however, and that is the question addressed here.

All parties now attempt to focus their local campaigning efforts on 'key' or 'target' seats and an initial general indication of the effects of campaigning can be obtained by comparing the parties' performances in their targets as opposed to other seats. Table 1 shows the overall change in vote shares for each of the parties in three categories of seat. ${ }^{3}$ At first sight, targeting by the Conservatives does not appear to have been very successful - the increase in their share of the vote in target seats was smaller than in the seats that they already held and almost the same as in those that they were unlikely to gain. On the other hand, Labour's worst performance by far was in the seats that they already held and did not target, while the decline in their vote share was smallest in their targets. The Liberal Democrats also did considerably better in their relatively small number of targets than in their safe or unlikely seats. This is at best indirect evidence of the effects of campaigning, however. In what follows, we discuss problems in measuring the impact of campaigning on electoral outcomes and present more direct evidence about the impact of constituency campaigning in the 2001 general election. 
TABLE 1

OVERALL CHANGE IN SHARE OF VOTES, 1997-2001 (TARGET AND NON-TARGET

SEATS)

\begin{tabular}{lcccc}
\hline & $\begin{array}{c}\text { Non-target } \\
\text { Held }\end{array}$ & Target & $\begin{array}{c}\text { Non-Target } \\
\text { Not Held }\end{array}$ & All \\
\hline Conservative & +2.6 & +0.3 & +0.2 & +1.2 \\
& $(164)$ & $(179)$ & $(294)$ & $(637)$ \\
Labour & -4.1 & -0.3 & -0.8 & -2.4 \\
& $(271)$ & $(147)$ & $(219)$ & $(637)$ \\
Lib Dem & +1.0 & +4.0 & +1.2 & +1.6 \\
& $(17)$ & $(58)$ & $(562)$ & $(637)$
\end{tabular}

Notes: The numbers of seats in the different categories are shown in brackets. Four constituencies are excluded from the calculations - West Bromwich West (Speaker's seat in 1997), Glasgow Springburn (Speaker's seat in 2001), Tatton (not contested by Labour and Liberal Democrats in 1997) and Wyre Forest (not contested by Liberal Democrats in 2001). 


\section{Measuring Campaign Intensity}

In order to assess the impact of campaigning, some measure of campaign intensity that can be applied across parties and constituencies is required. Johnston and colleagues have used campaign expenditure as a surrogate indicator, the assumption being that the more money a party spends in a constituency the stronger is its campaign and vice versa, while Seyd and Whiteley have used surveys of party members to estimate the activism of constituency organisations. Clearly, however, both of these are very indirect measures of campaign intensity.

Our studies of campaigning in the 1992, 1997 and 2001 general elections, on the other hand, have been based on nation-wide postal surveys of election agents - the people who organize and direct constituency campaigns - which asked them to provide details of their party's campaign in their constituency. ${ }^{4}$ This approach is not without difficulties, of course - we have to rely on respondents remembering the details and being honest, for example, and to concentrate mainly on activities during the 'short' campaign, even though local campaigning now begins well in advance of an election. Nonetheless, on the basis of the information provided by agents we have been able to construct various indices measuring the strength of the constituency campaigns conducted by the parties and have used these measures to analyse electoral effects. Our approach has the advantage of yielding direct measures of campaign intensity - being based on what actually happens on the ground in a constituency campaign rather than surrogates. Using our various indices we can compare campaign intensity across parties, across constituencies and, to some extent at least, in different elections.

In constructing our original campaign intensity index we used numerous variables from our surveys to create new variables measuring activity on seven dimensions of campaigning preparation, organisation, manpower, canvassing, leafleting, use of computers and the polling day operation. A principal components analysis of these seven variables generated one factor and factor scores for each case. These factor scores then constituted a standardized campaign strength score, with an overall mean of zero (for details see Denver and Hands, 1997: 24655). However, this original index of campaign intensity was devised with a very traditional constituency campaign in mind, and did not include measures of more modern techniques, such as telephone canvassing and direct mail. We have therefore expanded and up-dated the 
index to do this, and the scores that this produces for the 2001 general election (recalculated, for ease of comprehension, so that the mean score for all cases is 100) are shown in Table $2 .^{5}$

Variations in the intensity with which parties campaign across constituencies are considerable and produced by a number of factors, but by far the most important factor is the electoral status of the constituency - in particular, whether or not it has been 'targeted' by a party. All parties now identify target seats - those where there is a possibility that they might win (if challenging) or lose (if they are the incumbent) - and focus their resources and expertise on them. Table 2 shows the mean campaign intensity scores for each party in three types of seat in $2001 .^{6}$ The figures suggest that, overall, the Conservatives had the strongest campaigns in the 2001 election, with Labour a little behind. As in previous elections, the Liberal Democrats had much the weakest campaigns overall, but when it came to targeting they were very effective. The strongest campaigns of all were in Labour targets, though the campaigns in Conservative and Liberal Democrat targets were only a little less strong. It is noticeable that Conservative campaigns in their safest seats were also fairly strong, but weaker than in their target seats. In fact this represents something of a breakthrough for Conservative campaign strategists, since in previous elections their strongest campaigns have been in their safest seats, which was not an optimal distribution of campaign resources. The change in 2001 is the fruit of a long learning and teaching process that was undertaken in the party in the aftermath of 1997. 
TABLE 2

MEAN CAMPAIGN INTENSITY SCORES 2001

\begin{tabular}{lcccr}
\hline & $\begin{array}{c}\text { Non-target } \\
\text { Held }\end{array}$ & Target & $\begin{array}{c}\text { Non-Target } \\
\text { Not Held }\end{array}$ & All \\
\hline Conservative & 129 & 137 & 87 & 114 \\
Labour & 109 & 143 & 87 & 108 \\
Lib Dem & 114 & 136 & 74 & 80 \\
\hline
\end{tabular}




\section{The Impact of Constituency Campaigning}

When attempting to analyse the impact of campaigning on election results, it is clear that some measure of campaign intensity must be the independent variable - and here we use the updated index described above - and that some measure of party performance must be the dependent variable. What is not clear is how party performance should be measured.

Perhaps the most obvious measures of party performance to use in this context are changes in the share of the votes and of the electorate obtained as compared with the previous election. The meaning of both measures is easy to appreciate and they are simple to calculate. In their original work, Denver and Hands (1997: 276-8) argued that the change in share of votes received is actually an indirect consequence of the primary aim of campaigning - maximising the number of votes received - and that change in the share of the electorate was the more appropriate measure of party performance. Nonetheless, initially we look at both measures.

Table 3 shows first the bivariate correlations measuring the association between campaign intensity on the one hand and changes in share of vote and share of electorate in 2001 on the other, along with the relevant figures for changes in vote share in $1997 .^{7}$ In 1997 , variations in the changes in vote share won by Labour and the Liberal Democrats were significantly and positively related to variations in campaign strength. In contrast, the harder the Conservatives campaigned in 1997 the worse they did. The results for 2001 are rather different. There was no significant association between campaign intensity and change in vote share for any party, which is certainly grist to the mill of those who remain sceptical about the effectiveness of local campaigning. Even more surprisingly, for all three parties the correlation between campaign effort and change in share of the electorate in 2001 is significant but negative. The harder they campaigned, the more their share of the electorate declined. The effect of constituency campaigning, it appears, was to put voters off!

However, one needs to be careful in interpreting these results. There was a large fall in turnout in the 2001 election, and there is evidence to suggest that when a party is losing ground the loss is approximately proportionate to its previous strength. Thus, if Labour lost 20 per cent of its votes - not percentage points of vote share, but 20 per cent of the votes received in the previous election - in each constituency (the actual national figure in 2001 was 20.7 per cent) then that would have a greater impact in vote or electorate share terms in seats where it previously had, say, 30,000 votes (it would lose 6,000 votes) than it would in 
those where it had around 10,000 votes (the loss would be only 2,000 votes). An examination of relevant scatter diagrams based on the 1997 and 2001 election results suggests that an effect of this kind did operate in 2001. Due to the sharp decline in turnout, each party's share of the electorate declined and each lost most where it had previously been strong. The correlation coefficients measuring the relationship between 1997 share of the electorate and change in the share of the electorate between 1997 and 2001 were -0.38 for the Conservatives, -0.82 for Labour and -0.49 for the Liberal Democrats. In terms of vote share the situation is less clear. Again, Labour lost more where the party was previously strong and less where it had previously been weak (the correlation between previous share of the vote and change in share of the vote being -0.42), though in the case of the Liberal Democrats the effect was a good deal less strong (the correlation coefficient being -0.16). However, the Conservatives tended to improve most in vote share terms where they were already stronger and least where they had previously been weaker (coefficient of +0.20 ). 
TABLE 3

CAMPAIGN INTENSITY AND PARTY PERFORMANCE IN 1997 AND 2001

\begin{tabular}{lccc}
\hline & Conservative & Labour & Lib Dem \\
\hline $\begin{array}{l}\text { Campaign intensity and: } \\
\text { Change in share of vote }\end{array}$ & & & \\
$1992-97$ & $-0.32^{*}$ & $0.43^{*}$ & $0.32^{*}$ \\
$1997-2001$ & 0.07 & 0.04 & 0.08 \\
$\begin{array}{l}\text { Change in share of electorate } \\
\text { 1997-2001 }\end{array}$ & $-0.28^{*}$ & $-0.20^{*}$ & $-0.19^{*}$ \\
$\begin{array}{l}\text { Share of vote (controlling for share } \\
\text { in previous election) }\end{array}$ & & \\
$\quad \begin{array}{l}\text { 1992-97 } \\
\text { 1997-2001 }\end{array}$ & $0.11^{*}$ & $0.45^{*}$ & $0.42^{*}$ \\
$\begin{array}{l}\text { Share of electorate (controlling for } \\
\text { share in previous election) }\end{array}$ & -0.08 & $0.22^{*}$ & $0.34^{*}$ \\
1997-2001 & -0.27 & & $0.33^{*}$ \\
\hline
\end{tabular}

Note: $\quad$ Significant coefficients $(\mathrm{p}<0.05)$ are asterisked. 
Whatever the interpretation one puts on these effects, the impact of a party's previous strength or weakness can be taken into account in analysis by calculating partial correlation coefficients measuring the association between campaign intensity and share of vote or electorate in the election concerned while controlling for share in the previous election. The relevant coefficients are shown in the second part of Table 3. On this basis the picture is now a more familiar one. As in 1997 (and also in 1992), the intensity of Labour and Liberal Democrat campaigning is significantly associated with (what are effectively) changes in their shares of votes - although less strongly than in 1997 - and the same is true when change in the share of the electorate is the dependent variable. Variations in Conservative campaigning, on the other hand, are not systematically linked to variations in the party's performance across constituencies. To a considerable extent, then, at this relatively simple level of analysis the evidence suggests that the impact of constituency campaigning in 2001 was broadly similar to that found in the elections of the 1990s, if somewhat weaker. Before we can accept this conclusion, however, we need to take account of other variables that may have affected constituency results in 2001.

The first such variable is region. Over the country as a whole, the Conservative share of the vote rose by 1.2 per cent but the change ranged from -1.9 per cent in Scotland to +2.9 per cent in East Anglia. Labour's national change was -2.4 per cent, but this varied between 6.2 per cent in Wales and -0.1 per cent in the South West, while the Liberal Democrats ranged from +3.8 per cent in the North to -0.1 per cent in the South West, compared with an overall change of +1.6 per cent. On the assumption that these differences were not a product of regional differences in campaigning but reflected some other regional effects, we control for region in subsequent analyses.

The second variable to be incorporated is incumbency. There is clear evidence that, in general, incumbent MPs tend to do better in terms of vote change in successive general elections then do new candidates (Norton and Wood, 1992). In particular, 'first-time incumbents' - that is those who won the seat for the first time at the preceding election frequently experience a 'second-time surge' in support. The explanation usually given for this phenomenon is that at the first election the new candidate would almost always be replacing a well-established MP, likely to be well-known in the constituency. By the time of 
the second election the new MP would have had a chance to make his or her mark - becoming better-known through the local media, helping constituents with problems and so on. Whatever the reason, incumbency is certainly a local constituency influence on election outcomes.

Having made major gains in 1997, Labour and the Liberal Democrats had many more firsttime incumbents than usual in 2001 (and the Conservatives relatively few) and the expected incumbency effects are evident in the changes in vote shares obtained by Conservative and Liberal Democrat candidates. The overall change in vote share for Conservative nonincumbents was +0.5 per cent $(\mathrm{N}=500)$ while for all incumbents it was +2.8 per cent $(\mathrm{N}=139)$ and for those who were first-time incumbents it was +3.1 per cent $(\mathrm{N}=49) .{ }^{8}$ Similarly, the overall change in vote share for Liberal Democrat non-incumbents was +1.4 per cent $(\mathrm{N}=597)$ compared with +4.1 per cent $(\mathrm{N}=40)$ for all incumbents and +5.2 per cent $(\mathrm{N}=26)$ for first-time incumbents. In Labour's case, however, non-incumbents generally did better than incumbents. The change in vote share for the former was -1.6 per cent $(\mathrm{N}=259)$ compared with -2.6 per cent $(\mathrm{N}=379)$ for the latter. Nonetheless, first-time incumbents did best of all with a change of -1.0 per cent $(\mathrm{N}=195){ }^{9}$

In our first set of multivariate analyses, then, the predictor variables are region, personal incumbency and campaign intensity. Region is entered as a series of dummy variables (with the West Midlands, where the distribution of votes was close to the national figures, as the comparator region) and incumbency is a simple dichotomy, scoring 1 for all incumbents and 0 for non-incumbents. In addition, having established that previous party strength affected party performance in 2001 we incorporate share of the electorate in 1997 as a predictor. This has the advantage of effectively controlling for the range of social and demographic characteristics of constituencies which are associated in familiar ways with party support. The dependent variable, reflecting the discussion of preferred measures above, is share of the electorate obtained in 2001. A stepwise procedure was used and the results are shown in Table 4. 
TABLE 4

MULTIPLE REGRESSION ANALYSES OF PARTY PERFORMANCE IN 2001

\begin{tabular}{lccc}
\hline & Conservative & Labour & Lib Dem \\
\hline Constant & -0.03 & 1.28 & -0.48 \\
\% share of electorate 1997 & 0.81 & 0.64 & 0.61 \\
Personal Incumbency & 2.26 & 1.33 & 5.30 \\
Scotland & -1.82 & - & 0.77 \\
Wales & - & -1.15 & - \\
North & - & - & 1.26 \\
North West & -1.10 & -1.18 & \\
South East & -1.55 & - & - \\
Greater London & -1.35 & -0.81 & - \\
Campaign Intensity & $\mathbf{1 . 1 5}$ & $\mathbf{2 . 6 0}$ & $\mathbf{4 . 5 0}$ \\
Adjusted ${ }^{2}$ & 0.955 & 0.932 & 0.917 \\
(N) & $(373)$ & $(442)$ & $(430)$ \\
\hline
\end{tabular}

Notes: The coefficients shown are unstandardized. The campaign intensity scores have been divided by 100 so that the scale is close to those for the incumbency and regional variables. Only coefficients that are statistically significant $(p<0.05)$ are shown. The Conservative response from Wyre Forest constituency, where the election was highly atypical, has been excluded. 
Not unexpectedly, given that electorate share in 1997 is included as a predictor, the $\mathrm{r}^{2}$ statistic in all three cases is very large. Share in 1997 alone is a good predictor of share in 2001. On top of this, however, being an incumbent was worth an increase of over two per cent in electorate share to Conservatives, more than one per cent to Labour candidates and an impressive 5.3 per cent to Liberal Democrats. The Conservatives performed significantly worse in Scotland, the North West, South East and Greater London than in the West Midlands and Labour worse in Wales, the North West and Greater London. The Liberal Democrats, on the other hand, did significantly better in Scotland and the North. Controlling for all of these influences, variations in the intensity of constituency campaigns had a significant impact on the performances of all three parties: the better their campaigns, the better their performance. This is gratifying for those who have argued the 'revisionist' case in respect of constituency campaigning and also especially encouraging for the Conservatives, since it suggests that their efforts to improve constituency campaigning paid some dividends in 2001. To give a sense of the impact of campaigning in more familiar terms, the coefficients imply that taking 1997 performance, incumbency and region into account a weak Conservative campaign would, on average, have increased their share of the electorate by 0.6 per cent while a very strong campaign would have made for an increase of 2.0 per cent. This is not a massive difference, of course, but nonetheless one well worth having. Weak Labour campaigns, on average, increased the party's share of the electorate by 1.4 per cent while their strongest campaigns increased it by 4.2 per cent. For the Liberal Democrats the relevant figures are even more impressive at 1.9 per cent and 6.8 per cent. ${ }^{10}$ On these figures it would be hard to deny that constituency campaigning clearly affected constituency results in the 2001 election.

We repeated this analysis using first-time incumbency (rather than incumbency itself) as a predictor variable. In each case first-time incumbency is significant and the effect of including this variable is to reduce the size of the coefficient for campaign intensity. Indeed, in the case of the Conservatives the campaigning variable now becomes non-significant. ${ }^{11}$ How is this to be interpreted? We suggested above that incumbency is clearly a constituency-level factor affecting election results and we would argue that first-time incumbency can be interpreted as itself a campaigning effect. It is not the simple fact of being a first-time incumbent that affects voters but what the new incumbent has done after being first elected. In this context it is not dealing with individual constituents' problems that 
is important - even the most assiduous MP can only be in contact with a fraction of the electorate for this purpose and he or she is likely to disappoint a proportion of these - but getting publicity in local media, meeting groups of voters, holding meetings and improving the party organisation. In short, this amounts to campaigning. Indeed, after 1997 Labour's new incumbents were strongly encouraged by the party to devote a lot of time to their constituencies - even to the extent of being absent from Westminster on a regular and planned basis for the purpose, since their votes were not required in the House. Moreover, the videos that Labour distributed in 60 priority seats towards the end of the 2001 campaign strongly trumpeted the achievements of the local MPs, who had all been first elected in 1997 . We suggest, therefore, that in all parties the 'second-time surge' gained by first-time incumbents in 2001 is actually a longer-term campaigning effect and strengthens rather than weakens the argument that constituency campaigning makes a difference.

Thus far, we have been concerned with the effects of each party's campaign upon its own performance. Parties do not campaign in isolation, however. All mount some sort of campaign in every constituency. Focusing on constituencies for which we have campaign intensity scores for all three parties, Table 5 shows the extent to which, across constituencies, the strength of the parties' campaigning efforts were inter-related. As can be seen, variations in campaign intensity on the part of the Conservatives and Labour were not significantly related but the Conservatives and Liberal Democrats tended to campaign strongly or weakly in the broadly the same constituencies, reflecting the fact that in many seats they were in close competition while in safe Labour seats they were both out of the running. On the other hand, Labour and Liberal Democrat campaign intensities were negatively related. Where Labour campaigned strongly the Liberal Democrats tended to be weak and vice versa. This is partly a product of the structure of party competition in different constituencies, but it may also reflect an on-the-ground understanding that Labour would go easy where the Liberal Democrats were challenging Conservatives while the Liberal Democrats would return the favour in closely fought Conservative $v$ Labour contests. 
TABLE 5

CORRELATIONS BETWEEN CAMPAIGN INTENSITY SCORES

\begin{tabular}{lll}
\hline & Conservative & Labour \\
\hline Labour & 0.04 & - \\
Lib Dem & $0.40^{*}$ & $-0.28^{*}$ \\
\hline
\end{tabular}

Notes: $\mathrm{N}$ in all cases $=184$. Significant coefficients $(\mathrm{p}<0.05)$ are asterisked. 
In any event, it seems likely that a party's performance will also be affected by the campaigns of the other competing parties. In addition, their own results might be affected by whether or not they are campaigning against an incumbent MP. In Table 6, therefore, we present the results of further multiple regression analyses based on these constituencies. This enables us simultaneously to take account of the campaigns of all three parties and assess their effect on the performances of their opponents as well as their own. We include all three intensity scores in the equations, as well as the incumbency status of each party's candidate. Regional dummy variables were also included as before but coefficients are not reported in the table for the sake of clarity. ${ }^{12}$

In these cases, the effects of Conservative incumbency remained a significant positive influence on the party's performance and also tended to reduce Labour support (but not that of the Liberal Democrats). Labour incumbency had no significant effect at all, but Liberal Democrat incumbents not only increased their own electorate share significantly but also reduced the share obtained by Labour. The latter might be a reflection of some erstwhile Labour supporters making a tactical switch to the Liberal Democrats in order to ensure that the incumbent held the seat. As far as campaigning is concerned, the analyses again suggest that Conservative campaigning had a significant impact on support for the party. It had no effect, however, on the performance of the other parties whereas Labour and Liberal Democrat campaigning affected their own and each other's performance in the expected ways. The better Labour campaigned, the better their performance and the worse the result for the Liberal Democrats. Similarly, the stronger the Liberal Democrat campaign the better the party's performance and the worse the outcome for Labour. On the other hand, the Conservative vote seems to have been impervious to the campaigning efforts of the other parties.

On the basis of these equations we can now estimate the combined effect of Labour and Liberal Democrat campaigning on their respective shares of the electorate. Using the same method as above, having taken strength in 1997, incumbency and region into account, a strong Labour campaign and a weak Liberal Democrat campaign in a constituency would produce an increase of 1.8 per cent in Labour's electorate share and a decrease of -0.5 per cent in the Liberal Democrat share. Where there was a strong Liberal Democrat campaign 
and a weak Labour campaign, the effect would be a decrease of -4.2 per cent in Labour's share and an increase of 6.2 per cent in the Liberal Democrat share. 
TABLE 6

MULTIPLE REGRESSION ANALYSES OF PARTY PERFORMANCE IN 2001 (RESPONSES FROM ALL THREE PARTIES)

\begin{tabular}{lccc}
\hline & Conservative & Labour & Lib Dem \\
\hline Constant & -1.59 & 7.58 & 1.31 \\
\% share of electorate 1997 & 0.83 & 0.59 & 0.60 \\
Con incumbent & 2.13 & -1.49 & - \\
Lab incumbent & - & - & - \\
Lib Dem incumbent & - & -3.16 & 6.72 \\
Con Camp. Intensity & $\mathbf{1 . 6 9}$ & - & - \\
Lab Camp. Intensity & - & $\mathbf{2 . 0 1}$ & $\mathbf{- 1 . 5 3}$ \\
Lib Dem Camp. Intensity & - & $\mathbf{- 3 . 4 7}$ & $\mathbf{4 . 6 3}$ \\
Adjusted r & & 0.950 & 0.923 \\
(N) & $(183)$ & $(182)$ & $(182)$ \\
\hline
\end{tabular}

Notes: The coefficients shown are unstandardized. The campaign intensity scores have been divided by 100 so that the scale is close to those for the incumbency and regional variables. Only coefficients that are statistically significant $(\mathrm{p}<0.05)$ are shown. 
As before, we repeated these analyses using first-time incumbency for all three parties, rather than simple incumbency, as predictor variables. Once again the effect was to reduce the size of the coefficients describing the impact of campaign intensity on each party's own vote, with the Conservative coefficient becoming non-significant. ${ }^{13}$ As above, we would suggest that the first-time incumbency variables are to some extent acting as surrogate indicators of campaign intensity.

\section{Conclusion}

The evidence that we have presented on the effects of constituency campaigning is not as clear-cut for the 2001 general election as it was for 1992 and 1997. In the latter, no matter which dependent variable was used and irrespective of the kinds of analysis undertaken, there was little evidence of Conservative campaigning affecting the party's performance but it was clear that stronger Labour and Liberal Democrat campaigning in the constituencies produced better election outcomes for these parties. This analysis of the 2001 data has produced results that are less easy to interpret. In no case were variations in the simple change in the share of the vote obtained by a party significantly related to variations in the intensity of its campaigns and for all three parties more intense campaigning was associated with steeper falls in their shares of the electorate. When we took account of previous vote, however, Labour and Liberal Democrat campaigning did have a positive effect on performance but Conservative campaigning did not. When additional controls for region and incumbency were introduced in multiple regression analyses, however, campaigning proved to be significant for all three parties. Moreover, in cases where we were able also to control for the strength of campaigns mounted by the other parties and whether or not opposing candidates were incumbents, campaigning by each party significantly affected its own performance and, in the case of Labour and the Liberal Democrats, the performance of the other party.

How are these results to be interpreted? The very different context of the 2001 election appears to have affected the ability of the parties to mobilize support at local level. Labour was expected to win easily and after 1997 had disappointed some of the party's core supporters. Labour campaigners may, therefore, have found it more difficult to galvanize voters through local campaigning. It seems likely, too, that the much larger number of seats targeted than in the past contributed to some dispersal of resources and that more focused campaigning would have made more impact. Despite these problems, once previous strength 
is taken into account variations in the intensity of Labour campaigning did affect the party's performance across constituencies, even if the impact was less striking than in previous elections. The Liberal Democrats were the only party whose support increased during the election campaign. In part, no doubt, this was due to the vigorous national campaign mounted by Charles Kennedy, to whom the electorate increasingly warmed. With increasingly receptive voters and, yet again, a very strong focus on relatively few target seats, the Liberal Democrats were able to make their campaigning skills count. According to our analyses, the difference made by intense Liberal Democrat campaigns to their performance was consistently greater than the difference made by strong Labour campaigns to theirs. There is little doubt that constituency campaigning by the Conservatives was better organized and more targeted on key constituencies in 2001 than in the past. Even so, evidence that Conservative campaigning made a difference to the performance of the party is relatively slight - although the fact that there is some evidence is encouraging. It would appear that improved constituency campaigning was not enough to overcome serious problems relating to the party's image and deficiencies in the national campaign strategy. In the past we have suggested that it is difficult to find a campaigning effect for the Conservatives because the kind of people who vote Conservative are likely to turn out and vote irrespective of the strength of the local campaign whereas those who vote Labour or Liberal Democrat, for different reasons, are less likely to come out and support the party if not effectively mobilized. We have seen that Conservative voters were apparently unmoved by the campaigns of their opponents, which is in line with this argument. On this occasion, however, they were encouraged to vote Conservative in somewhat greater numbers where a strong constituency campaign took place.

The context of the next general election is likely to be similar to that of 2001. By that time Labour may find it even harder to mobilize supporters, the Liberal Democrats will be further stretched over a larger number of seats and the Conservatives will again have to aim to recapture a large number of seats. Resolving these problems will not be easy for any of the parties but, given the evidence presented here, it seems likely that the ways in which constituency campaigns are organized at national level and the strength of campaigning on the ground will once again have a significant effect on the election outcome. 


\section{ACKNOWLEDGEMENT}

The research on which this article is based was supported by the ESRC (grant reference number R000239396).

\section{FOOTNOTES}

1. For an extended discussion of the somewhat counter-intuitive results for the Conservatives in 1992 see Denver and Hands (1996).

2. For a detailed discussion of the targeting strategies of the parties see Denver et al. (2002, forthcoming).

3. Labour's list of 148 target or 'priority seats' is public knowledge - it comprised the 146 seats gained in 1997 plus Boston \& Skegness and Dorset South, both very narrowly held by the Conservatives in 1997. About 180 Conservative targets were initially chosen simply on the basis of the size of the incumbent party's percentage majority so that it is 'not rocket science', as a national official put it, to identify them. We have assumed that the list comprised the 179 seats in which the Conservatives came closest to the winner (in terms of percentage majority) in 1997 plus Romsey, which had been lost in a by-election. The Liberal Democrats had a more elastic conception of what counted as a target seat, but following discussions with party officials we have identified 58 seats targeted by the Liberal Democrats in one way or another. Although the 'official' list of Liberal Democrat targets remains confidential, it contains few surprises.

4. The surveys covered Conservative, Labour, Liberal Democrat, SNP and Plaid Cymru agents. The overall response rates from the three main parties were $53.0 \%$ in $1992,68.5 \%$ in 1997 and $65.6 \%$ in 2001.

5. The expansion of the index involves adding two new campaign dimensions - one relating to targeting of leaflets and use of direct mail and the other concerning the use of telephones for canvassing (both before and during the campaign) and knocking up. In addition, the preparation dimension is extended to include the extent of use of previous canvass records and the extent to which voter identification had been undertaken in the pre-campaign period. The canvassing dimension now takes the percentage of the electorate canvassed by telephone into account; the use of party software is added to computers and the polling day dimension also includes whether volunteers were sent into the constituency from neighbouring seats.

6. The numbers of responses on which the data in Table 2 are based are as follows: 


$\begin{array}{lcccc} & \begin{array}{c}\text { Non-target } \\ \text { Held }\end{array} & \text { Target } & \begin{array}{c}\text { Non-Target } \\ \text { Not Held }\end{array} & \text { All } \\ \text { Conservative } & 122 & 103 & 150 & 375 \\ \text { Labour } & 183 & 96 & 164 & 443 \\ \text { Lib Dem } & 10 & 33 & 389 & 432\end{array}$


7. Major changes to constituency boundaries in 1997 make it impossible in many cases to calculate changes in the share of the electorate. We have expanded the campaign intensity index for 1997 in the same way that we did for 2001. The coefficients for the Conservatives are based on 434 responses in 1997 and 374 in 2001. For Labour the respective numbers are 455 and 442, and for the Liberal Democrats 411 and 430.

8. Given that the Conservatives gained no seats in 1997 it may seem odd that we have classed 49 candidates as first-time incumbents. These include new candidates in seats already held before 1997, candidates elected in by-elections between 1997 and 2001 and a number who moved to a new constituency in 1997 following the extensive boundary revisions. The latter may have been MPs before 1997 but in 2001 they were first-time incumbents in their new constituencies.

9. In the aftermath of the election there was much comment on how well Labour's first time incumbents had done. This impression was created by focussing on the seats that Labour had gained in 1997 and in these the decline in vote share was indeed smaller than in other seats (0.5 per cent, $\mathrm{N}=144$ ). However, there were a number of new candidates in 1997 in seats that Labour already held who were also first-time incumbents in 2001 and the change in their overall vote share was -2.1 per cent $(\mathrm{N}=51)$.

10. The estimates for each party are calculated by applying the coefficients for campaign intensity to the mean of the twenty worst and twenty best intensity scores for each party.

11. The coefficients for first-time incumbency are 1.28 for the Conservatives, 1.35 for Labour and 4.85 for the Liberal Democrats. The coefficients for campaign intensity are 1.84 for Labour and 4.17 for the Liberal Democrats; the coefficient for the Conservatives was not significant.

12. Of the original 184 cases for which we have three responses, West Bromwich West is excluded because it was the Speaker's seat in 1997. Tatton was also not contested by Labour or the Liberal Democrats in 1997 and is excluded from the analysis of their performance.

In the Conservative equation, Scotland and the South East had significant negative coefficients while those for the North and Wales were positive and significant. For Labour, Wales was significantly negative and the South West significantly positive. No regional variable was significant in the case of the Liberal Democrats.

13. The coefficient for Labour campaign intensity is now 1.31 and that for the Liberal Democrats 4.43. The coefficient showing the impact of Liberal Democrat campaigning on the Labour vote $(-3.50)$ was similar to that in the original equation but that showing the impact of Labour campaigning on the Liberal Democrat vote also decreased (-1.39). 


\section{REFERENCES}

Denver, D. and Hands, G. (1996) 'Constituency Campaigning in the 1992 General Election: the Peculiar Case of the Conservatives', in D. Farrell, D. Broughton, D. Denver and J. Fisher (eds) British Elections and Parties Yearbook 1996, pp. 85-105, London: Frank Cass.

Denver, D. and Hands, G. (1997) Modern Constituency Electioneering, London: Frank Cass.

Denver, D. and Hands, G. (1998) 'Constituency Campaigning in the 1997 General Election: Party Effort and Electoral Effect' in I. Crewe, B. Gosschalk and J. Bartle, (eds) Why Labour Won the General Election of 1997, pp. 75-92, London: Frank Cass.

Denver, D., Hands, G., Fisher, J. and MacAllister, I. (forthcoming, 2002) 'Constituency Campaigning in 2001' in J. Bartle, R. Mortimore and S. Atkinson (eds) Political Communications, London: Frank Cass.

Denver, D., Hands, G. and Henig, S. (1998) 'Triumph of Targeting? Constituency Campaigning in the 1997 Election', British Elections and Parties Review, 8: 171-90.

Norton, P. and Wood, D. (1992) 'Do Candidates Matter? Constituency-Specific Vote Changes for Incumbent MPs, 1983-87', Political Studies, XL: 227-38.

Pattie, C. J, Johnston, R. J. and Fieldhouse, E. A. (1995) 'Winning the Local Vote: The Effectiveness of Constituency Campaign Spending in Great Britain, 1983-1992', American Political Science Review, 89 (4): 969-83.

Whiteley, P. and Seyd, P. (1994) 'Local Party Campaigning and Voting Behaviour in Britain', Journal of Politics, 56: 242-51. 